\title{
MANERAS DE TRABAJAR. SANTAFÉ DE BOGOTÁ (SIGLO XVIII)
}

\author{
Pilar López-Bejarano \\ ICANH (Colombia) \\ ORCID: https://orcid.org/0000-0002-8975-6626 \\ pilarlb@uniandes.edu.co
}

Este texto indaga la organización del trabajo en Santafé de Bogotá a finales del siglo XVIII. Combinando fuentes administrativas, judiciales, parroquiales, crónicas y relatos de viajeros, se exponen tres rasgos característicos de la actividad laboral en la ciudad: las dinámicas mestizas, el carácter múltiple y cambiante y la débil asociación en torno a los oficios. Se propone - con el análisis de una red de zapateros - ir más allá de la aproximación al trabajo a partir de categorías de oficios, para profundizar en entramados sociales que permitan articular, en sus complejidades, los trabajos de hombres y mujeres y las relaciones de trabajo con otras jerarquias y sociabilidades como el parentesco, la vecindad, la estratificación racial o la fidelidad a un patrón.

Palabras Clave: Trabajo, Santafé de Bogotá, categorías sociales, historia relacional, siglo XVIII.

\section{Ways of Working in 18Th Century SANTAFE DE Bogota}

This paper explores work organization in Santafe de Bogota at the end of the 18th century. Upon mixing sources of administrative and judicial nature as well as church archives, chronicles, and traveler's narratives, three key features of urban labor are highlighted: the dynamics of mixed peoples, its plural and changing nature, and the weak connections in trade fields. Through the analysis of a shoe-maker's guild, this paper goes beyond trade categories, delving into complex social networks involving both female and male labor, as well as connections between work, social hierarchies, sociability, kinship, racial stratification and loyalty to the chief.

KEYWORDS: Labor, Santafe de Bogota, Social Categories, Relational History, 18th Century. 
Preguntarse por el trabajo de un grupo humano es también preguntarse cómo vive, es decir, no solo cómo subsiste económicamente y que oficios y actividades ejerce, sino también preguntarse de qué manera las personas ejercen estas actividades y qué tipo de vínculos establecen entre ellas para realizarlas. En esta perspectiva, un estudio sobre el trabajo de los santafereños resulta ser también una reflexión sobre sus sociabilidades y asociaciones, sobre sus dependencias y autonomías, sobre las trayectorias históricas que conformaron sus características, sus limitaciones y sus recursos de vida.

El presente texto retoma parte de una investigación doctoral en historia social realizada bajo la dirección de Juan Carlos Garavaglia. ${ }^{1}$ Proponerlo en el contexto de este homenaje ${ }^{2}$ es una manera de resaltar una característica de su trabajo como historiador y como profesor: su constante esfuerzo por dar cuenta del aspecto social de toda historia económica, así como del aspecto económico de toda historia social (política, cultural o jurídica). Bajo su dirección, mi proyecto inicial de doctorado organizado a partir de una perspectiva cultural, se orientó rápidamente hacia una concepción holista de la sociedad que no concebía dejar de lado lo económico, imaginando que este no era su «tema». Es así como para pensar la pereza como valor en el siglo XVIII, tema inicial de la tesis, resultó indispensable interesarse por el trabajo. En evidente resonancia con muchas de las batallas que marcaron el derrotero de Juan Carlos docente e investigador, mi inicial interés por «la pereza» desembocó — a lo largo de la investigación doctoral — en una reflexión profundamente social y relacional sobre el trabajo, bien lejos de lecturas meramente productivistas o clasificatorias. Justamente, en esta línea de pensamiento que tanto interesaba a Juan Carlos, proponemos aquí este texto.

Se inicia ubicando la ciudad de Santafé de Bogotá en su contexto virreinal y monárquico, se indica su vocación económica y el proceso que llevó a que a finales del siglo XVIII estuviera habitada por una población mayoritariamente libre y mestiza. Enseguida se busca identificar los oficios y actividades de hombres y mujeres del pueblo, aproximación realizada a partir de un censo de milicias urbanas y de un censo de barrio. Con la anterior información y recurriendo a otro tipo de fuentes (archivos judiciales, censos, relatos de viajeros, archivos parroquiales), se averiguan las maneras de trabajar y las formas de asociación que predominaron en el mundo laboral de la ciudad para, al final del texto, abordar el caso de un grupo de zapateros de un barrio popular.

1. López Bejarano, Pilar, «Hommes fainéants et indolents, femmes dissolues...»Paresse et travail à Santa Fe de Bogota (Nouvelle Grenade), XVIII siècle, thèse de doctorat, Paris, EHESS, 2007. Publicada en castellano como: Gente ociosa y malentretenida: Trabajo y pereza en Santafé de Bogotá, siglo XVIII», Bogotá, Universidad de los Andes, Ediciones Uniandes, 2019.

2. «Sociedades, mercancías y formación estatal en América Latina: los mundos de Juan Carlos Garavaglia», 10 y 11 de octubre de 2018, Universitat Pompeu Fabra, Barcelona. 


\section{La ciudad}

Santafé de Bogotá era una de las capitales del amplio y heterogéneo Imperio español. En el siglo XVIII aparece como un centro urbano medio si lo comparamos con otras ciudades americanas, no rivalizaba ni en tamaño ni en riqueza ni en importancia, con ciudades como México o Lima; no obstante, y a pesar de su modesto lugar en el contexto ibérico, su función como sede administrativa de la Corona le daba cierta prestancia: primero como capital de la Audiencia de Santafé, dependiente del virreinato del Perú y después a partir de 1739, como capital del virreinato de Nueva Granada. ${ }^{3}$ Al ser centro administrativo, Santafé jugaba un papel mediador tanto en las prácticas de gobierno como en las dinámicas de la economía virreinal, en particular en la de la explotación aurífera que fue centro de interés colonial; ${ }^{4}$ aunque en sus alrededores no hubo minas de oro, desde la capital se encauzaban productos agrícolas para las zonas mineras y se acuñaba el oro en su central Casa de la Moneda, circuitos que favorecían su actividad comercial. ${ }^{5}$

La existencia de una importante población india en la provincia y en general en toda la región andina del virreinato, marcó las características de su instalación colonial, de su economía y por lo tanto de sus relaciones de trabajo. Las instituciones de la Encomienda y de la Mita se asentaron plenamente en el poblado altiplano andino, territorio de grupos indígenas muiscas o chibchas. Desde tiempos prehispánicos la vocación económica de este territorio incluyó la elaboración de textiles, la producción de sal, así como una abundante y variada agricultura donde los pueblos situados a diferentes altitudes permitieron amplias gamas de productos. ${ }^{6}$ La ubicación de la ciudad de Santafé en el altiplano andino marcaba también las posibilidades de su interconexión con otras regiones del virreinato y de la monarquía. ${ }^{7}$ Recordemos que Santafé se encontraba a una altura de 2.600 m y a 1.154 kilómetros de su principal puerto marítimo y plaza mayor, Cartagena de Indias. Los productos importados, en particular de Castilla, eran por lo tanto más costosos y esto se aplicaba también a la importación de mano de obra esclava: la distancia del puerto de llegada aumentaba considerablemente su precio. ${ }^{8}$

En el siglo XVIII, los trabajos en la ciudad abarcaban una amplia gama que combinaba mediano y pequeño comercio, actividades artesanales, un notable abanico de servicios, así como actividades ligadas a la construcción y al mantenimiento de caminos o de

3. Vargas, Julián, «Santa Fe a la luz de sus padrones», en La Sociedad de Santa Fe colonial, Bogotá, CINEP, 1990, pp. 11-45.

4. Jaramillo, Jaime, «La economía del virreinato (1740-1810)», en Ocampo, José Antonio (ed.), Historia económica de Colombia, Bogotá, Siglo Veintiuno Editores - Fedesarrollo, 1987.

5. Kalmanovitz, Salomón y Edwin López, «La economía de Santafé de Bogotá en 1810», Revista de Historia Económica, vol. 30, n. ${ }^{\circ}$ 2, 2012, pp. 191-223.

6. McFarlane, Anthony, Colombia antes de la Independencia, economía, sociedad y politica bajo el dominio borbón, Bogotá, Banco de la República - El Áncora Editores, 1996, pp. 91-93.

7. Colmenares, Germán, «La economía y la sociedad coloniales, 1550-1800», en Nueva historia de Colombia, t. I, Bogotá, Planeta, 1989; Palacios, Marco y Frank Safford, Colombia: país fragmentado, sociedad dividida, Bogotá, Editorial Norma, 2002.

8. McFarlane, Anthony, Colombia antes de la Independencia..., cit., p. 20. 
edificaciones públicas y privadas. Estas actividades eran realizadas por una creciente proporción de gente pobre ajena a las formas obligatorias de trabajo que habían primado en siglos anteriores (encomienda, mita). Los censos de final del siglo XVIII reflejan una mayoritaria población «libre»: mestizos, mulatos, zambos, negros libres, indios desagregados y blancos. ${ }^{9}$ El censo del año 1779 indica, por ejemplo, que de una población censada de 16.419 habitantes, un $40 \%$ eran parte de los llamados «libres de todos los colores», un $46 \%$ era denominado como «blancos», un $10 \%$ de población estaba clasificada como india y un $4 \%$ esclava. En el entorno rural el porcentaje de «libres» era de un $60 \%$ (38\% de «libres de todos los colores» y $22 \%$ de «blancos»), un más significativo $39 \%$ de población india y un mínimo $1 \%$ de población esclava. ${ }^{10} \mathrm{El}$ crecimiento, el mestizaje y la evolución de la población en la ciudad y en la provincia fueron procesos articulados.

La ciudad se inscribía en la vida rural con vínculos frecuentes y fluidos. Entre las haciendas de la sabana, los pueblos de resguardo, las parroquias, las comarcas y la ciudad, la relación no era solamente aquella de un hinterland que proveía alimentos a la ciudad, sino que existió una gran movilidad de trabajadores tanto para el servicio, como en el pequeño comercio y la construcción. Estos trabajadores de Santafé podían ser tenderos y hacendados, peones rurales y urbanos, revendedores que circulaban entre la ciudad y los pueblos vecinos. Incluso dentro de la misma ciudad, las fronteras entre lo urbano y lo rural no se presentaban de manera tajante. Los solares se mezclaban con las zonas de habitación, muchas casas tenían grandes patios en los que se construían corrales para los animales, huertas y cultivos para el consumo diario, esta condición de «ciudad rural» se mantuvo hasta bien avanzado el siglo XIX. ${ }^{11}$

Con lo dicho se entiende que — a nivel de las relaciones de trabajo- la ciudad no presentaba un rasgo predominante o de fuerte sometimiento. Para la época hablamos de una población relativamente pequeña, en comparación con las capitales o ciudades centrales de Hispanoamérica, ${ }^{12}$ una población altamente mezclada, con una economía fundamentalmente local de pequeño comercio y de servicio, ambos aspectos relacionados con su papel de centro de gobierno virreinal.

9. Tovar Pinzón, Hermes, Camilo Tovar y Jorge Tovar (comp.), Convocatoria al poder del número. Censos y estadísticas de la Nueva Granada 1750-1830, Bogotá, Archivo General de la Nación, 1994, pp. 63-86.

10. Vargas, Julián, «Santa Fe a la luz de sus padrones (1778-1806)...», cit., pp. 20-24.

11. Holton, Isaac, La Nueva Granada, veinte meses en los Andes, Bogotá, Banco de la República, 1981.

12. Desde el punto de vista del tamaño, Santafé de Bogotá se ubicaba —a finales del siglo XVIII- como intermedia en el conjunto de las ciudades hispanoamericanas. A la cabeza estaba México con 113.000 habitantes en 1790; la seguían ciudades cuya población oscilaba alrededor de los 50.000 habitantes, como Lima, La Habana, Santiago de Chile o Caracas. Por debajo figuraban aquellas con una población que oscilaba alrededor de los 25.000 habitantes, entre ellas Mérida, Quito, Buenos Aires, Guatemala, Potosí, Cuzco, La Paz y Santafé de Bogotá, ubicada en la parte inferior de este conjunto, con una población de cerca de 18.000 habitantes en 1793. Ver: Sánchez-Albornoz, Nicolás, La población de América Latina: desde los tiempos precolombinos al año 2000, Madrid, Alianza Editorial, 1973, p. 150. 


\section{Los trabajadores}

Dos registros urbanos nos permitirán acercarnos a los hombres y mujeres que trabajaron en Santafé a finales del siglo XVIII. El primer registro es el del batallón Auxiliar de Milicias formado por artesanos; el segundo es el de un censo del barrio Las Nieves, lugar de habitación de la mayoría de los trabajadores de la ciudad. Ciertas precisiones sobre estos dos conjuntos de datos son necesarias.

1. Trabajamos sobre las listas de milicias del año 1783 en las que se registran 517 hombres. ${ }^{13}$ Las milicias urbanas se fundaron en la capital como parte de un proyecto para disciplinar a los artesanos y para asegurar el orden público que se había visto perturbado con la revuelta de los Comuneros del año $1781 .^{14}$ Las instrucciones dadas en 1781, momento de su constitución, permiten conocer los criterios de elección de los hombres convocados para integrarlas. Se trataba de artesanos y pequeños comerciantes «gente urbana de Santafé», decía la orden, aclarando que se requerían solamente los «hombres blancos, casados o solteros, entre 15 y 45 años»; se indicaba igualmente que debía ponerse cuidado en la «solidez, fuerza, agilidad, honestidad y fidelidad» de los reclutas, dejando de lado «los cortos de talla, viejos y achacosos». ${ }^{15}$ Entonces, aunque estas listas nos ilustran sobre ciertos artesanos y comerciantes de la ciudad, no se pueden hacer generalizaciones inmediatas ni al conjunto de los artesanos, ni al conjunto de la población, pues en ellas está ausente el trabajo femenino, el de los niños, el de los mayores de 45 años, y el de los indios, mestizos y mulatos (aunque como veremos más adelante el postulado criterio de blancura no excluye las mezclas entre los milicianos).

2. Para completar estos datos — en particular en lo que atañe al trabajo de las mujeres y de las «castas»— consideramos, al lado de las listas de milicias, un censo del barrio Las Nieves. ${ }^{16}$ Este censo no está fechado, Julián Vargas en su texto Santafé a la luz de sus padrones da la fecha de 1780, mientras que Virginia Gutiérrez y Roberto Pineda señalan un intervalo bastante amplio e indefinido entre el final del siglo XVIII y el inicio del XIX. ${ }^{17}$ Tampoco se indica el motivo de su realización, los folios conservados corresponden básicamente al centro del barrio, es decir a las manzanas alrededor de la calle principal. ${ }^{18}$ Como el de las milicias, este listado tampoco es exhaustivo. Para empezar, los datos solicitados, como el número de la casa, el oficio, nombre y apellido solo corresponden a las cabezas de hogar, situación que reduce la información sobre los trabajadores del barrio.

13. AGN, Milicias y Marina t. 18, ff. 51-69.

14. Trato este tema en otro artículo: López-Bejarano, Pilar, «Control y desorden en Santa Fe de Bogotá (Nueva Granada). En torno a las Reformas urbanas de finales del siglo XVIII», BROCAR - Cuadernos de Investigación Histórica, vol. 30, La Rioja, 2006, p. 125.

15. AGN, Milicias y Marina t. 12, ff. 370-382.

16. AGN, Milicias y Marina t. 141, ff. 151-162.

17. Vargas, Julian, «Santafé a la luz de sus padrones...», cit., p. 12; Gutiérrez, Virginia y Roberto Pineda, Miscegenación y cultura en la Colombia colonial. 1750-1810, t. 1, Bogotá, Uniandes-Colciencias, 1999, p. 393.

18. El documento conservado es sin duda un borrador, pues cada hoja esta tachada de un extremo al otro y la secuencia de datos se interrumpe de manera abrupta. Tampoco hay encabezado ni firma del alcalde o funcionario que lo realizó. 
No obstante, y a pesar de sus límites, es evidente que permite conocer aspectos de una parte de los habitantes de este barrio y ciertos indicios sobre la conformación de los hogares y las características de la vecindad. Otros censos de finales del siglo XVIII, indican que en el barrio Las Nieves vivía alrededor del $30 \%$ de los habitantes de la ciudad, concentrando buena parte de la población trabajadora. ${ }^{19}$ Las listas de milicias confirman esta fuerte presencia de artesanos y de pequeños comerciantes: de los 517 milicianos, 211 vivían en el barrio Las Nieves, repartiéndose el resto en los otros 5 barrios de la ciudad (Príncipe, Catedral, Santa Bárbara, San Victorino, San Jorge).

Una vez considerados los límites y las posibilidades de estos documentos, veamos qué pueden decirnos acerca de los hombres y mujeres que trabajaban en Bogotá.

\section{Los oficios}

Empezamos con las listas de milicias. Al lado del nombre, el origen, la edad, el estado (casado o soltero), el barrio y la calle de habitación, estas listas registraron los oficios de los milicianos. La primera característica que aflora de este recuento es la predominancia de cinco actividades: sastres, albañiles, zapateros, carpinteros y comerciantes. De los 517 milicianos enlistados, 498 declararon un oficio y de estos más de la mitad, 282, declaró ejercer una de estas cinco actividades (tabla 1), los restantes 216 milicianos declararon 51 oficios menos frecuentes.

TABLA 1. Oficios inscritos en las listas de milicias de la ciudad (1783)

\begin{tabular}{|c|c|c|c|}
\hline OFICIO & CANTIDAD & OFICIO & CANTIDAD \\
\hline sastre & 75 & fresadero & 2 \\
\hline albañil & 71 & molinero & 2 \\
\hline zapatero & 46 & peluquero & 2 \\
\hline carpintero & 46 & petaquero & 2 \\
\hline tratante & 44 & tejedor & 2 \\
\hline labrador & 24 & truquero & 2 \\
\hline platero & 19 & adobero & 1 \\
\hline pulpero & 15 & agente & 1 \\
\hline barbero & 13 & alarife (maestro de obra) & 1 \\
\hline estudiante & 12 & cerero & 1 \\
\hline jornalero & 12 & cohetero & 1 \\
\hline tejero & 11 & comerciante & 1 \\
\hline escribiente & 9 & enfardelador & 1 \\
\hline sombrerero & 8 & farolero & 1 \\
\hline
\end{tabular}

19. Correo Curioso Erudito, Económico y Mercantil, n. ${ }^{\circ} 5$ y 6, marzo de 1801, edición facsímil, Bogotá, Biblioteca Nacional - Colcultura, 1993. 


\begin{tabular}{lclc}
\hline \multicolumn{1}{c}{ OFICIO } & CANTIDAD & OFICIO & CANTIDAD \\
\hline herrero & 7 & fundidor & 1 \\
músico & 7 & hortelano & 1 \\
dorador & 6 & ingeniero & 1 \\
talabartero & 6 & lapidario & 1 \\
vago & 6 & locero & 1 \\
leñatero & 4 & maestro de escuela & 1 \\
peón & 4 & montero (cazador) & 1 \\
amanuense & 3 & plumero & 1 \\
cantero & 3 & receptor & 1 \\
mercader & 3 & tapicero & 1 \\
panadero & 3 & tasador & 1 \\
pintor & 3 & tendero & 1 \\
empleado & 2 & tintorero & 1 \\
curtidor & 2 & tresadero & 1 \\
\hline
\end{tabular}

FuENTE: A partir de AGN, Milicias y Marina, t.18, ff. 51 à 69.

Tanto la confección de vestidos y calzado, como el comercio y las obras de arquitectura urbana en las que se aplicaban según este recuento estos trabajadores-milicianos, daban cuenta de las prácticas de consumo en la ciudad y de su crecimiento urbano a finales del siglo XVIII. ${ }^{20}$ Aunque, como ya se indicó, estas listas se refieren solamente a los hombres del pueblo que en el momento pudieron ser catalogados como blancos. Insistimos en el límite de esta fuente porque es común encontrarla en estudios sobre artesanos y trabajadores o en referencia generales al pueblo santafereño en el siglo XVIII, considerándola como muestra representativa del conjunto de la ciudad; lo que tiende a distorsionar la visión que podemos llegar a tener.

Veamos ahora el censo del barrio Las Nieves, como lo hicimos para las listas de milicias, presentamos los oficios y actividades que en él se registraron:

TABLA 2. Oficios registrados en el censo del barrio Las Nieves

\begin{tabular}{llll}
\hline HOMBRES: & & & \\
zapateros & 22 & mataganado & 2 \\
sastres & 15 & polvoreros & 2 \\
hacendados & 12 & maestro escuela & 1 \\
albañiles & 10 & mantero & 1 \\
carpinteros & 10 & alpargatero & 1 \\
\hline
\end{tabular}

20. Kalmanovitz, S. y E. López, «La economía de Santafé de Bogotá en 1810...», cit., p. 192. 


\begin{tabular}{|c|c|c|c|}
\hline \multicolumn{4}{|l|}{ HOMBRES: } \\
\hline tratantes & 9 & aserrador & 1 \\
\hline plateros & 7 & cajeros & 1 \\
\hline sombrereros & 7 & cantero & 1 \\
\hline pulperos & 6 & carbonero & 1 \\
\hline mieleros & 4 & comerciante & 1 \\
\hline oficiales & 3 & escribano & 1 \\
\hline pintores & 4 & escultores & 1 \\
\hline revendedor & 1 & fresador & 1 \\
\hline talabarteros & 3 & fuelleros & 1 \\
\hline labradores & 3 & guarda & 1 \\
\hline tejedores & 3 & hortelano & 1 \\
\hline amanuenses & 2 & impresor & 1 \\
\hline barberos & 2 & militar & 1 \\
\hline batihojas & 2 & sacristán & 1 \\
\hline contadores & 2 & soldado & 1 \\
\hline curtidores & 2 & tintorero & 1 \\
\hline enfardeladores & 2 & tiplero & 1 \\
\hline fundidores & 2 & fundero & 1 \\
\hline \multicolumn{4}{|l|}{ MUJERES: } \\
\hline costureras & 10 & planchadora & 1 \\
\hline tabaqueras & 9 & chichera & 1 \\
\hline amasadoras & 9 & maestra & 1 \\
\hline lavanderas & 6 & jornalera & 1 \\
\hline hilanderas & 4 & fundera & 1 \\
\hline revendedoras & 3 & panadera & 1 \\
\hline tenderas & 3 & & \\
\hline
\end{tabular}

FueNTE: AGN, Milicias y Marina t. 141, ff. 151 a 162.

Al observar los oficios en las dos tablas anteriores, la primera evidencia es que con el registro barrial el espectro se abre a los oficios y labores de las mujeres: tabaqueras, lavanderas, tenderas, amasadoras, hilanderas o costureras. Constatamos además que cambian las proporciones en los oficios masculinos: de una mayoría de sastres entre los milicianos, pasamos a una mayoría de zapateros entre los jefes de familia del barrio. También aparecen oficios ausentes entre los milicianos: mataganado, mielero, revendedor, carbonero. Hay del mismo modo, ocupaciones que desaparecen —estudiante, músico o peluquero-, oficios que de hecho tampoco están presentes en la porción de milicianos que habitaba el barrio Las Nieves. Llama igualmente la atención en el censo barrial la importante proporción de mujeres jefes de hogar: de los 439 hogares censados 201 (46 \%) son declarados por una mujer cuyo trabajo representaba la única o la más importante fuente de ingresos del núcleo familiar. En general madres solas con sus hijos (75\%), de común en- 
tre 2 y 5, llegando a declarar hasta $11 .{ }^{21}$ Otro censo de la época sobre el mismo barrio, el Censo de Forasteros de año 1801, refuerza esta imagen de una significativa presencia de mujeres solteras, viudas o que estando casadas «no hacían vida con sus maridos»; entre los forasteros los porcentajes son más importantes, del total de forasteros censados $68 \%$ eran mujeres, y de estas solamente el $8 \%$ hacían vida conyugal. ${ }^{22}$

Conviene detenerse un momento en la particularidad sociológica del papel central de las mujeres en el mundo del trabajo santafereño, en las repercusiones que necesariamente tuvo en la configuración general de las relaciones de trabajo en la ciudad. ${ }^{23}$ Mas allá de las diferencias en los tipos de actividades realizadas, considerar el trabajo femenino obliga a repensar aspectos como los tiempos de trabajo, sus mecanismos de acceso, las diferentes dimensiones de lo que podía significar socialmente trabajar o no trabajar, implica ampliar la mirada a una dinámica económica de la ciudad capaz de superar una concepción sesgada y tipificada del trabajo urbano, un análisis capaz de pasar de relaciones más o menos institucionalizadas, a la relativa indefinición de actividades productivas y reproductivas, públicas y privadas. ${ }^{24}$ Tomemos el caso de las «amas de cría» del Hospicio Real, aunque en ningún momento los documentos las nombran como realizando un trabajo, ni ellas lo declaran como tal, estas mujeres recibían un sueldo del gobierno por amamantar y criar a los niños expósitos. Era en efecto muy común que la práctica de un trabajo quedara velada al no asignarle un estatus susceptible de ubicarla como un oficio, un negocio o cualquier otra actividad productiva, o que quedara escondida detrás de una imagen conveniente de mujer en el hogar.

Volviendo al censo, vemos que sobre los 201 jefes de hogar que no declaran un oficio, el $77 \%$ son mujeres. Las razones de esta situación pueden ser diversas y van del simple hecho de que el alcalde, o la persona que realizó el censo, no obtuvo la información o no preguntó de manera que le permitiera obtenerla, hasta la posibilidad de que buena parte

21. Es imposible pasar por alto el vínculo entre la estructura matrilocal de las comunidades indígenas del altiplano y las prácticas matrimoniales de este barrio mestizo. Tener hijos por fuera del matrimonio o vivir con su familia en lugar de hacerlo con su marido, respondía a la estructura familiar indígena y era una situación más que común y aceptada en el contexto popular y mestizo del barrio.

22. AGN, Policía, t. 11, ff. 242-272.

23. La importante presencia de mujeres jefes de hogar en la Nueva Granada. Cf., Dueñas, Guiomar, Los bijos del pecado, ilegitimidad y vida familiar en la Santa Fe de Bogotá colonial, Bogotá, Universidad Nacional, 1997; Ramírez, María Himelda, Las mujeres y la sociedad colonial de Santa Fe de Bogotá, 1750-1810, Bogotá, ICANH, 2000, pp. 117-125. Puede enmarcarse en una tendencia similar estudiada en otros trabajos sobre América ibérica colonial. Cf. Alberro, Solange, «Familia y trabajo en la Nueva España, las ambigüedades del tema», en França Paiva, Eduardo y Carla Anastasia Jubho (eds.), O Trabalho Mestiço. Maneiras de Pensar e formas de viver, séculos XVI a XIX, São Paulo, Annablume - Universidade Federal de Minas Gerais, 2002, pp. 513-524; Russell-Wood, A. J. R., «La mujer y la familia en la economía y en la sociedad del Brasil durante la época colonial», en Lavrin, Asunción (ed.), Las mujeres latinoamericanas, perspectiva histórica, México, Fondo de Cultura Económica, 1985, pp. 74-120.

24. En torno a estas preguntas se puede ver el acercamiento que he hecho al trabajo y a la posición de una mujer chichera del barrio Las Nieves en otro artículo: López-Bejarano, Pilar, «Dinámicas mestizas, Tejiendo en torno a la jerarquía, al trabajo y al honor. Nueva Granada, siglo XVIII», NuevoMundo, Mundosnuevos, Paris, 2008, en línea: <http://nuevomundo.revues.org/index19263.html>. 
de estas mujeres viviesen efectivamente sin ejercer un oficio (por ejemplo vivir de arriendos o del trabajo de hijos o parientes). Sin descartar las anteriores opciones, y considerando lo ya dicho sobre la invisibilidad del trabajo femenino, nos damos cuenta de que dos actividades descritas en diferentes documentos como las más corrientes entre las mujeres del pueblo no aparecen entre los oficios que registra el censo. Nos referimos al servicio domestico y a la preparación y venta de alcoholes: aguardiente y chicha. Con respecto a la primera es cierto que si estar al servicio de alguien indicaba una actividad o un «destino», también lo es que esta actividad no entraba dentro de la categoría «artes y oficios», lo que explica que las actividades de servicio no estén señaladas como oficio en el censo; otra razón es que la labor de servicio doméstico (servicio en casas, en conventos o monasterios) ocupaba principalmente a jóvenes o niñas indígenas o en ciertos casos a población esclava, población que este censo no registra. En cuanto a la segunda, la realización y venta de chica y aguardiente, la recurrencia de quejas contra las chicheras y las chicherías, las Órdenes o Bandos reglamentándolas o prohibiendo este tipo de comercio, hablan de esta actividad como una de las más importantes fuentes de trabajo y de entradas económicas de las mujeres del pueblo. ${ }^{25}$ La mala reputación que acompañaba estas actividades, así como el carácter ilegal de la destilación de aguardiente, dan razones de su ausencia en el censo a pesar de que era evidente que muchas debían ser chicheras; Encontramos unos años más tarde a una de ellas, Josefa Moreno, que en el censo aparece sin oficio ${ }^{26}$ en un proceso judicial donde su condición de chichera se encuentra en el centro del conflicto. ${ }^{27}$ Otro dato que nos orienta a pensar que detrás de la ausencia de oficio declarado puede existir el oficio de chichera, es que entre las mujeres jefes de hogar que no declaran ningún oficio, más de la mitad declaran vivir en una tienda (el censo registra dos tipos de vivienda: casa o tienda, siendo la segunda también un local comercial), lugar donde comúnmente se comercializaba la chicha.

Las anteriores consideraciones nos incitan a no aferrarnos (en el análisis) a los oficios registrados en estas listas como si fuesen la expresión única y necesaria de toda actividad laboral, como si fuesen la actividad definitiva y permanente que otorgaba identidad a las personas. ${ }^{28}$ Por esa razón en las páginas que siguen abordamos nuestra problemática desde otro ángulo: pasamos a considerar las relaciones que nos hablan no solo del tipo de oficio realizado sino, además, de las maneras de ejercerlo.

25. Dueñas, G., Los hijos del pecado..., cit.; Vargas, Julián, La sociedad de Santa Fe Colonial, Bogotá, CINEP, 1990; Alzate, Adriana, «La chicha: entre bálsamo y veneno. Contribución al estudio del vino amarillo en la región central del Nuevo Reino de Granada, siglo XVIII», Historia y Sociedad, n. 12, Bogotá, 2006, pp. 161-189.

26. AGN, Milicias y Marina t. 141, f. 162.

27. AGN, Civiles, t. 7, f. 257-318. Ver igualmente López-Bejarano, Pilar, «Dinámicas mestizas...», cit.

28. Una interesante reflexión histórica sobre los oficios y los ciclos de vida en: Lévi, Giovanni, «Carrières d'artisans et marché du travail». Annales ESC, vol. 6, Paris, 1990, pp. 1351-1368 y Cerutti, Simona, «Du corps au métier: la corporation des tailleurs à Turin entre XVII et XVIII siècle», Annales ESC, vol. 2, Paris, 1988, pp. 323-352. 


\section{Maneras de trabajar}

La manera como se trabajaba en Santafé tenía su fundamento en el propio proceso histórico de conformación de su población. A finales del siglo XVIII las relaciones de trabajo se tejían tanto desde su secular posición colonial, como desde un significativo crecimiento urbano acompañado de marcados procesos de mestizaje. La particularidad de sus relaciones de trabajo se vivía además con una renovada visión que pretendía trabajadores especializados, agremiados y disciplinados, pensamiento que puede ubicarse dentro de lo que los historiadores José Carlos Chiaramonte para Iberoamérica y Renán Silva para la Nueva Granada ha estudiado como la «crítica ilustrada de la realidad», percepción en la que nuevos ideales —entre ellos el del «trabajo útil y educador»- dieron orden a una renovada lectura de la sociedad. ${ }^{29}$ En este contexto de superposición de hábitos y de innovaciones, las maneras de trabajar de los santafereños aparecían especialmente inadecuadas para gobernantes y reformadores ilustrados. De un lado, ya no cuadraban con las instituciones de trabajo obligatorio en decadencia y, del otro, respondían aún menos a las expectativas ilustradas del deber ser de los trabajadores, expectativas formalizadas en discursos, proyectos gremiales y control de la población..$^{30}$ Teniendo en mente este proceso general precisaremos, a partir de vínculos sociales de trabajo, tres formas características que dan cuenta de las maneras de trabajar de los santafereños a finales del siglo XVIII.

\section{El trabajo mestizo}

Un proceso de mestizaje en una sociedad estamental no señala solamente las variaciones en la pertenencia «socio-racial», ni solamente la hispanización de indígenas y afrodescendientes, indica igualmente la transformación de la estructuración social y en este sentido un cambio de configuración que incluye las relaciones de trabajo. ${ }^{31}$ La lógica es simple: si el orden social se apoyaba en divisiones estamentales y en jerarquías entre grupos de pertenencia, la atenuación y la confusión entre los grupos redefinía necesariamente las maneras de relacionarse y entre ellas las maneras de trabajar. ${ }^{32}$

Un primer elemento a tener en cuenta en la situación tardo-colonial de una mayoría mestiza para el trabajo, es que a diferencia del trabajo indígena o esclavo no existió para los mestizos un marco jurídico que estableciese un deber susceptible de convertirse en

29. Silva, Renán, «La crítica ilustrada de la realidad en las sociedades andinas», en Garrrido, Margarita (ed.), Historia de América Andina, vol. 3: El sistema colonial tardio, Quito, Universidad Andina Simón Bolívar, 2001, p. 367.

30. López-Bejarano, P., «Control y desorden en Santa Fe de Bogotá...», cit.

31. França Paiva, Eduardo y Carla Anastacia Jubho (eds), O Trabalbo Mestiço..., cit.; Gruzinski, Serge y Carmen Bernard, Histoire du Nouveau Monde, II Les métissages, Paris, Fayard, 1993, pp. 222-286.

32. Serulnikov, Sergio, «El fin del orden colonial en perspectiva histórica. Las prácticas políticas en la ciudad de La Plata, 1781-1785 y 1809», Revista Andina, n. 52, Cusco, 2015, pp. 9-47; López Bejarano, Pilar, «Dinámicas mestizas...», cit., en particular el ítem: Dinámicas de estratificación social en América colonial. 
obligación, ni unas pautas particulares que reglamentaran su ejecución. Desde 1647 la Política Indiana de Solórzano y Pereyra ${ }^{33}$ ubicaba el trabajo mestizo bajo las mismas condiciones de libertad y de sujeción que tenía el de los blancos pobres, fuesen españoles o criollos (L.II, c.V). En este sentido se puede decir que jurídicamente (en comparación con los indios y los esclavos) estos trabajadores eran libres. De hecho, esta era una de las maneras de referirse a ellos: «los libres». Expresión que no debe comprenderse fuera de su contexto, puesto que esta libertad hacía referencia estrictamente al aspecto jurídico. Como en cualquier gobierno de antiguo régimen, en la Santafé colonial ser «libre» se entendía asumiendo la general posición de todo habitante del virreinato de ser «vasallo» del Rey. A partir de esta posición general de sujeción a un monarca, se declinaban diversas formas de sujeción, de sometimiento y de dependencias. En este contexto, la creciente población de «libres» participaba de la vida social y económica de la ciudad tanto enmarcada en diversas formas de dependencia y de servidumbre, como desde la posición jurídica de estar exenta de tributos y obligaciones particulares.

Claro está que la distinción entre libertades y sujeciones era más difusa en las prácticas de lo que establecía la ley: la impronta de los trabajos obligatorios y de la esclavitud repercutía inevitablemente en las condiciones del trabajo «libre». El deber «natural» de trabajar de la población indígena fue comúnmente requerido entre los mestizos de las «castas», el «derecho» de quienes durante generaciones gozaron de privilegios, o de las gracias del acceso al trabajo indígena, siguió enraizado en las costumbres y en las prácticas cotidianas. ${ }^{34} \mathrm{El}$ paradigma del trabajo obligatorio estaba presente ya fuese por el tipo de trabajo que unos esperaban de otros, como por la conciencia de la diferencia que separaba a los «libres» de los obligados: no ser esclavo, no ser tributario, cuando había otros que sí lo eran y lo estaban, contaba mucho en la manera como se percibían y eran percibidos unos y otros. ${ }^{35}$

Con este acervo (dominación, herencias ibéricas, mestizajes, criollización) y estas complejidades (libertades, dependencias, dominación), planteamos el trabajo mestizo en la ciudad a finales del siglo XVIII. En su misma conformación los procesos y las modalidades no fueron homogéneas en todos los oficios. La debilidad de los gremios que encontramos a finales del siglo XVIII contrasta con su relativa presencia en los siglos XVI y XVII; ${ }^{36}$ la paulatina desaparición de una vida gremial promovida y sostenida por la presencia de

33. Solórzano y Pereyra, Juan, Política Indiana, Madrid, Biblioteca de autores españoles t. 253, 1972.

34. Una suposición y expectativa del mismo tipo se produjo en el siglo siguiente con los ex-esclavos y con sus descendientes, aunque declarados jurídicamente libres se siguió esperando de ellos dedicación «natural» al trabajo.

35. Para esta consideración resultaron muy esclarecedores los trabajos de Moses Finley sobre la esclavitud y en general sobre las formas se servidumbre en el mundo antiguo: Finley, Moses, L'économie antique, Paris, Minuit, 1973. Igualmente, el libro de Testart, Alain, L'esclavage, la dette et le pouvoir, Paris, Errance, 2001, en especial el capítulo «l'esclavage comme institution».

36. Los archivos notariales del Archivo General de la Nación dan cuenta de esta paulatina desaparición de la vida gremial promovida y sostenida por la presencia de artesanos españoles y en general europeos. Véase igualmente Rodríguez, Diana, El trabajo artesanal en Santafé durante la primera mitad del siglo XVII: sastres, zapateros y sombrereros, Bogotá, Tesis de maestría en historia, Universidad de los Andes, 2015, p. 20. 
artesanos españoles y en general europeos, nos muestra cómo el mestizaje de la ciudad transformó también sus maneras de trabajar. En algunos oficios como la platería, en el trabajo de metales en la Casa de la Moneda o en la sastrería se guardó cierta cercanía con las formas de trabajo europeas; ${ }^{37}$ en otros oficios desde muy temprano se impuso la manera local, tanto por ser desempeñados por población india como por inscribirse en las instituciones de trabajo obligatorio colonial, las cuotas de pueblos de indios de la provincia se renovaban cada dos meses, situación que dificultaba la especialización y la organización social en torno a los oficios; ${ }^{38}$ lógicamente esta organización de las relaciones de trabajo impedía los procesos de agremiación, ya que la misma modalidad de trabajo basado en el tributo iba en contra de duraderos tejidos laborales.

\section{La actividad múltiple}

El trabajo mestizo se expresó en formas de trabajar heterogéneas e inestables. A finales del siglo XVIII encontramos pocos rastros de especialización en los oficios desempeñados por la mayoría de mestizos libres; aparte del trabajo de metales que necesitaba ciertos grados de especialización y dedicación exclusiva, lo común era que cada persona desempeñara actividades paralelas, siendo una de ellas el oficio que en determinado momento pudo declarar. También ocurría que los oficios declarados aparecieran como una pura formalidad sin relación directa con las formas de ganarse la vida. Esta última situación aparece con frecuencia entre hombres y mujeres enjuiciados por delitos menores, donde se declaraba un oficio que en realidad no se ejercía. En casos menos extremos, vemos más bien el cambio de un oficio a otro o la combinación de actividades. Así, por ejemplo, Juana Rosa Rodríguez acusada en 1781 de «amancebamiento público y notorio», se ocupaba de una tienda de chichería al mismo tiempo que servía en una casa de familia; ${ }^{39}$ José de Adminahorta se dedicaba a la práctica cotidiana y fija de servir a Don Antonio Barrientos, lo cual no le impedía paralelamente vender miel en la tienda del propietario de la casa donde alquilaba una pieza;0 María Rosa Salgado reclamaba en 1874 el salario de sus servicios de costura y de crianza de los hijos de Don Luis Azula, ubicándose en este reclamo al mismo tiempo como costurera, ama de crianza y sirvienta; ${ }^{41}$ Juana María Caicedo, acusada en 1800 por heridas, declara ser chichera, costurera y planchadora, en el

37. Fajardo de Rueda, Marta, Oribes y plateros en la Nueva Granada, León, Universidad de León, 2008; Bonnett, Diana, «Oficios, rangos y parentesco. Los trabajadores de la Casa de la Moneda de Santafé 16201816», Historia y Memoria, vol.6, Bogotá, 2013, pp. 103-141.

38. Zambrano, Marta, «Trabajo preciosos y trabajadores despreciables: prácticas conflictivas y consenso epistémico en el discurso colonial», ACHSC vol. 25, Bogotá, 1998, pp. 6-34. Y Zambrano, Marta y Julián Vargas, «La población indígena de Santafé», en La sociedad de Santafé colonial, Bogotá, CINEP, 1990, pp. 47 84.

39. AGN, Policía, t. 3, f. 361.

40. AGN, Testamentaria, t.13, ff. 234-248.

41. AGN, Testamentaria, t. 8, f. 928. 
mismo proceso María de los Reyes Neyra dice ser tabaquera y planchadora, mientras que Fabiana Poveda es presentada como chichera y polvorera. ${ }^{42}$

Es evidente que la variabilidad aumentaba cuando el oficio era poco especializado o cuando la precariedad imponía la inestabilidad laboral. Policarpo Moreno, mestizo de 16 años, de oficio «cargador de agua», se empleó en varios momentos como sirviente en casas de familia, obrando también en varias ocasiones como «mandadero» o «peón», en tareas puntuales. ${ }^{43}$ La polifonía de maneras de ganarse la vida daba cuenta de la inestabilidad social de estos trabajadores, de su falta de formación y del hecho de ser muy mal pagados en cada una de ellas. No obstante, las situaciones de cambio no se limitan a los más pobres y vulnerables, también entre los oficios prestigiosos se variaba con frecuencia: José María Caballero, Maestro Mayor de sastrería y figura central en la organización gremial de este oficio, tenía también una pulpería en la calle Santa Clara y una tienda de géneros de Castilla en la Plaza Mayor; posición en dos frentes que, sin embargo, no le impidió que en un momento de su vida partiera como vendedor ambulante de «abarrotes y trebejos» a Tunja, Sogamoso y Susacón, o incluso que pudiera «servir», en la preparación de fiestas y celebraciones de la ciudad. ${ }^{44}$

Los casos enunciados son evidentemente variados y variables, no obstante, se puede realizar una tentativa de visión general por la negativa. Esto es: la constatación de que no estamos en la lógica de grupos ocupacionales bien compartimentados, controlados y organizados según una evolución progresiva interna. En el caso de los oficios menores, la lógica parece más bien aquella del «rebusque», se hace lo que se puede en itinerarios sinuosos e inciertos. El oficio declarado más que un rasgo de definición o de identidad representaba entre estos trabajadores una posibilidad, una carta entre otras, un aspecto que no decidía completamente o definitivamente el rumbo de sus vidas. Ahora bien, si el oficio no era más que un elemento entre otros, cabe preguntarse por el tipo de asociación que en ese momento dinamizaba el mundo del trabajo; pregunta que nos remite, en última instancia, a las relaciones sociales que sustentaban el actuar de los trabajadores en la ciudad.

\section{La asociación}

Los bajos grados de asociación en torno al trabajo que develan las dinámicas laborales de la ciudad, se relacionan con la movilidad que acabamos de ver. La modalidad de trabajo agremiado (con sus jerarquías, sus reglamentos y controles) no llegó a tener un peso significativo, solamente, como ya lo indicamos, lo pudo tener en algunas labores prestigiosas; pero en regla general no se actuaba en función de este tipo de organización, no se

42. AGN, Criminales, t. 73, ff. 646-668.

43. AGN, Criminales, t. 100, f. 4.

44. Caballero, J. M., Particularidades de Santa Fé, un diario de José María Caballero, Bogotá, Biblioteca Popular de Cultura Colombiana, 1946. 
recurría a los exámenes de conocimientos y habilidades para el ejercicio de los oficios. ${ }^{45}$ Si ciertos estatus y jerarquías se plasmaron en documentos y se usaron en los tratos, no hay evidencia de que fueran propiamente resultado de una dinámica de trabajo gremial. Tomemos el ejemplo de los albañiles.

A partir de unos informes de obras gubernamentales es posible observar la evolución de algunos individuos dentro del oficio de albañil. Manuel Zamorano y Josef Suarez «oficiales», el uno albañil y el otro carpintero, en $1789,{ }^{46}$ son ya «maestros», en otra obra del año $1795 .{ }^{47}$ Nicolás León «asistente albañil», en la misma obra del año 1789, realiza un avalúo como «maestro mayor», en 1825.48 ¿Debemos ver en estos casos la prueba de una organización que regulaba la evolución de los individuos dentro de los oficios? No parece pertinente ir tan lejos, en primer lugar porque las listas evocadas se inscriben en la experiencia de un pequeño círculo de trabajadores de la construcción que, dada su proximidad con las formalidades de la administración real, alcanzaban un grado de organización que no se puede comparar al del resto de los trabajadores de la ciudad. Además, se puede añadir que incluso en este exclusivo contexto de las obras reales, nada nos permite deducir que estas evoluciones y adquisición de nuevos estatus fueran exclusivamente resultado de una estructura corporativa de albañiles o de carpinteros. ${ }^{49}$ Otros elementos sociales pudieron influir en la expresión de jerarquías según títulos gremiales como peón, oficial o maestro.

Veamos algunos indicios de estas complejidades sociales. Dado que a finales del siglo XVIII los detalles prácticos del proceso de aprendizaje y de evolución dentro de un oficio fueron raramente evocados, tomaremos referencias de inicios del siglo XIX cuando la organización de los artesanos despertó mayor interés entre los contemporáneos. José María Cordovez Moure, cronista santafereño, describió las maneras de trabajar de los albañiles de la ciudad: el futuro maestro albañil — dice— se inicia como «chino de zurrón», encargado de cargar y descargar la tierra y los otros materiales necesarios; si le agrada al maestro de obra es promovido a peón de tercera clase, es decir que hace la misma actividad pero al lado de los «oficiales» de la obra. En esta proximidad aprende lo

45. Este tipo de exámenes prácticos de un oficio solo lo encontramos en referencia a los trabajadores de metales preciosos, concretamente a los plateros y a los trabajadores de la Casa de la Moneda (AGN, Miscelánea t. 2, ff. 929-1641 y Moneda, t. 1, ff. 490-491, 740-773); ver igualmente Fajardo de Rueda, Oribes y plateros en la Nueva Granada..., cit. y Bonnett, «Oficios, rangos y parentesco...», cit.

46. AGN, Mejoras Materiales, t. 9, ff. 638-649.

47. AGN, Miscelánea, t. 37, ff. 755 y 756.

48. AGN, Notaría 3. ${ }^{\circ}$, t. 366 (1825), f. 211.

49. La situación pudo variar en contextos institucionalizados y regulados en la misma capital o en otras ciudades neogranadinas. Así el caso de los trabajadores de la Casa de la Moneda o el de los trabajadores del Apostadero de la Marina en Cartagena. Para estos últimos se documentan desde finales del siglo XVIII relaciones de trabajo que ya toman las características que van a ser la norma a lo largo del siglo XIX. Aunque la influencia de estos contextos especializados sobre el resto de los trabajos pudo ser variable, es innegable que su sola existencia daba otras complejidades a los mundos laborales. Ver Solano, Sergio, «Artesanos, Jornaleros y formas concertadas de trabajo: el Apostadero de la Marina de Cartagena de Indias (Nuevo Reino de Granada) en el tránsito entre los siglos XVIII y XIX», THEOMAI, vol. 31, Cartagena, 2015, pp. 79-105. 
que puede: «cuando sabe colocar un adobe sobre otro y manejar la llana con alguna destreza» se califica a sí mismo de «oficial» y empieza a perfilarse como potencial rival de su «maestro»; si en este estado llega a surgir algún inconveniente o altercado, sin formalidad alguna se gradúa a sí mismo con el título de «maestro» y se va de la obra, a menudo acompañado de otros trabajadores listos a seguirlo. ${ }^{50}$ No hay duda de que esta descripción es generalizadora y casi caricatural, no obstante, sin tomarla a la letra muestra una lógica existente de aprendizajes no regulados, de alianzas y separaciones que dependen más de lealtades personales a un patrón que de regulaciones organizativas. En este orden de cosas, se entiende que en 1807 un peón de albañil, Joaquín Zifuentes, pudiera proponerle a un conocido, Policarpo Moreno, enseñarle «el oficio». ${ }^{51}$

Si entre los albañiles pobres las jerarquías gremiales del oficio podían estar muy poco estructuradas, en otros oficios como en el de zapatero parecían tener aún menos peso. De hecho la única referencia tardo-colonial que encontramos de rangos dentro del oficio (maestros, oficiales, etc.) es en 1791 la de un francés residente en la ciudad: «Nicolás Bourgues, Maestro de zapatería, natural de los reinos de Francia». ${ }^{52}$ Esta ausencia se relacionaba seguramente con el hecho de ser una actividad menos prestigiosa, desempeñada por personas de rangos inferiores y sin la relación a la administración colonial como la tuvieron los carpinteros y albañiles. En la tradición ibérica ya era un oficio menor y en la ciudad de Bogotá — en particular en los barrios pobres_-, era realizada por población mestiza y mulata. Julián Vargas en un estudio sobre un corpus de 100 procesos criminales a población india a lo largo del siglo XVII señala que un $16 \%$ eran zapateros ${ }^{53}$ y en las listas que hemos examinado para el siglo XVIII la presencia mestiza y mulata se confirma para este oficio.

Del lado de los sastres, como entre los albañiles, encontramos un amplio abanico de posibilidades. Dos imágenes opuestas nos llegan a través de los documentos estudiados. Por un lado, un oficio prestigioso ejercido por hombres blancos trabajado para altos funcionarios y gente «principal» de la ciudad, talleres dirigidos por maestros sastres, guiando la labor de oficiales y aprendices. Una imagen representativa de este grupo es la que nos podemos hacer de José María Caballero, maestro sastre capitalino que dejó un diario en el que da cuenta de su participación en la vida social y política de la elite de la ciudad. ${ }^{54}$ En un documento de 1804 se habla de un gremio de sastres, este documento que propone la formación de un montepío aparece firmado por 16 maestros (entre ellos José María Caballero) y afirma que el gremio se conforma de 50 hombres entre maestros y oficiales. ${ }^{55}$ Por otro lado, la imagen opuesta del mismo oficio, sastres pobres completamente integrados al modo de vida de la plebe urbana. Este aspecto del oficio aparece en

50. Codovez Moure, J. M. «Artes, ciencias y oficios», en Reminiscencias de Santafé y Bogotá, Bogotá, Librería Americana, 1899, pp. 256-259.

51. AGN, Criminales, t. 100, f. 5.

52. AGN, Miscelánea, t. 2, f. 799.

53. Vargas, Julián La sociedad de Santafé colonial..., cit., p. 83.

54. Caballero, J. M., Particularidades de Santa Fé..., cit.

55. AGN, Miscelánea, t. 3, f. 264 a 268. 
los datos registrados por el censo barrial de Las Nieves, donde ni en la «calidad» de las personas, ni los lugares de habitación o los niveles de remuneración se distancia del de zapateros, cargadores o albañiles. ${ }^{56}$ De estos sastres pobres J. Steuart nos da una imagen en un relato del año 1836; a pesar de ser posterior al periodo que aquí estamos viendo, lo evocamos por considerar que en lo que se refiere a estos artesanos la situación y sus formas de trabajo no debieron cambiar mucho, ni con los esfuerzos reformadores de finales del siglo XVIII, ni con la Independencia. Dice Steuart: «En un taller se hacinan hasta tres o cuatro hombres, sentados en butacos bajos, todos apeñuscados frente a la puerta, el único lugar a través del cual puede entrar la luz. Dan una puntada por minuto, pues emplean un ojo en el trabajo y otro en la calle»; igualmente señala que estos artesanos pobres producían ropa ordinaria y barata, situación que se adaptaba bien, nos dice, a las posibilidades de la mayoría de los habitantes de la ciudad. ${ }^{57}$ Así las cosas, decir sastre estaba lejos de designar un grupo unido y homogéneo de personas en la ciudad o de hacer referencia a «un» tipo de actividad o a una posición determinada en las dinámicas configuracionales de la ciudad.

Afirmar que el modelo gremial no decidía el orden laboral en Santafé, no quiere decir sin embargo caos y anomia en el mundo del trabajo. Necesariamente, el trabajo tenía formas particulares de orden. Se abre la pregunta si, como en otras ciudades americanas o europeas de la época, existió un ordenamiento espacial de los oficios en determinadas calles o barrios. La nomenclatura urbana nos da algunas pistas, mínimas: en el barrio La Catedral la calle de los Plateros y la de los Herreros. ${ }^{58}$ Con esta inquietud sobre una organización espacial de los oficios revisamos las listas de milicia y el censo del barrio Las Nieves, encontramos algunas coincidencias puntuales entre los oficios y las calles de habitación, pero nada que señale un rasgo significativo; la única constatación es que en su mayoría estos trabajadores vivían y tenían sus talleres por fuera del núcleo central de la ciudad, en barrios periféricos como Las Nieves, Santa Bárbara o San Victorino, pero dentro de esos barrios las ocupaciones no aparecen ubicadas en sectores bien definidos; donde hay coincidencias en la lista de milicias (1783) no existen en el censo del barrio, por lo que tenderíamos a pensar que estas agrupaciones asociadas a un lugar de la ciudad no permanecían.

Si la vecindad en función del oficio no parece imponerse, aparece en esta indagación una posible relación del oficio en función de la vecindad. Vemos por ejemplo la cercanía de costureras y sastres de la calle San Luis del barrio las Nieves, las primeras en las casas 14 y 20, los segundos en las casas 13 y 23. Buscamos otros vínculos: Nicolasa Rojas (sin oficio declarado) que vive en la casa 4 de la calle del Chorro, tiene un hijo sastre; su veci-

56. AGN, Milicias y Marina t. 141, ff. 151 a 162.

57. Steuart, John, Narración de una expedición a la capital de la Nueva Granada y residencia allí de once meses. Bogotá en 1836-37, Bogotá, Academia de Historia/Tercer Mundo, 1989, pp. 130-131.

58. Para los plateros de Santafé, Marta Fajardo de Rueda afirma que, aunque estaba mandado se concentrasen en un barrio, los plateros instalaron sus talleres en diversos puntos de la ciudad Fajardo de Rueda, Marta Oribes y plateros en la Nueva Granada..., cit., p. 53. 
na (seguramente pariente) Josefa Rojas, que vive en la casa 2 de la misma calle, es costurera. Se trata de pequeños detalles que llaman la atención sobre los posibles vínculos entre oficios, parentesco y vecindad. Cruzamos entonces datos de registros parroquiales, con la información que traen para el barrio Las Nieves los registros ya examinados de milicias y censo. Aparecen otros vínculos: Josef Thomas Rodríguez, joven sastre en la lista de milicias en $1783,{ }^{59}$ nombra madrina de uno de sus hijos (en 1808) a Josefa Rojas, costurera y vecina de su misma calle. ${ }^{60}$

Otro ejemplo lo tenemos en uno de los oficios que vimos como el más frecuente en el censo barrial, el de zapatero. Identificamos cuatro zapateros Almanza: dos en la lista de milicias (Manuel y Joseph Casimiro) y dos en el Censo (Pedro y Pablo). A partir de aquí y con la información de matrimonios y bautismos de los libros parroquiales, llegamos a reconstituir no solo la red familiar de los Almanza, sino los vínculos con otras familias por alianza o padrinazgo.

\section{Los zapateros Almanza}

La familia Almanza tejió vínculos especialmente cercanos con la familia Rozo y Barbosa, todos habitantes del mismo barrio (parte occidental del barrio Las Nieves). Estos apellidos asociados por alianza a los Almanza, los encontramos igualmente entre los zapateros del censo barrial y de milicias: dos zapateros Rozo, el primero Joseph Custodio Rozo, hijo de Francisca Almanza, hermana de Manuel y de Pedro, y el segundo, Joseph Ignacio Rozo, padrino del hijo de María Barboza, hija de Petrona Almanza (otra hermana de Manuel y de Pedro Almanza). En las mismas listas aparece otro hijo de Petrona Almanza, también zapatero, Francisco Barboza, quien es además compadre de su tío zapatero Pedro Almanza. En la reconstitución de vínculos de parentesco aparece una cuarta familia, los Gaona, que a diferencia de los anteriores no figuran como zapateros en las listas analizadas.

Con esto datos realizamos un diagrama (figura 1). Con el, con la trama que designa, se multiplican las preguntas. Se buscó completar la información sobre otros eventuales oficios ejercidos por los miembros de estas familias o definir las calles donde habitaban, pero a pesar del esfuerzo de reunir diferentes tipos de fuentes los datos resultan escasos. No obstante, las relaciones puntuales que se pudieron establecer, así como la visión de conjunto que proporciona esta red, permite algunas reflexiones a propósito de sus sociabilidades y alianzas, de las jerarquías intrafamiliares por oficio, por castas o lugar de residencia; de la incidencia de la vecindad, del parentesco o del apadrinamiento en sus tejidos sociales.

El primer aspecto a considerar es que lo que aparecía en las listas como una familia de zapateros, una vez reconstituida en una red más amplia de entramados interpersonales, resulta ser un tejido de familias donde ser zapatero fue «una» de las opciones entre las actividades productivas que ciertos miembros ejercieron. La información disponible

59. Con 16 años en 1783 , suponemos que era aún aprendiz.

60. Archivo de la Parroquia de Nuestra Señora de las Nieves (APN), 1808, Libro 09B, f. 50v. 
FIgURA 1. Diagrama de familias de Zapateros, barrio las Nieves (siglo XVIII).

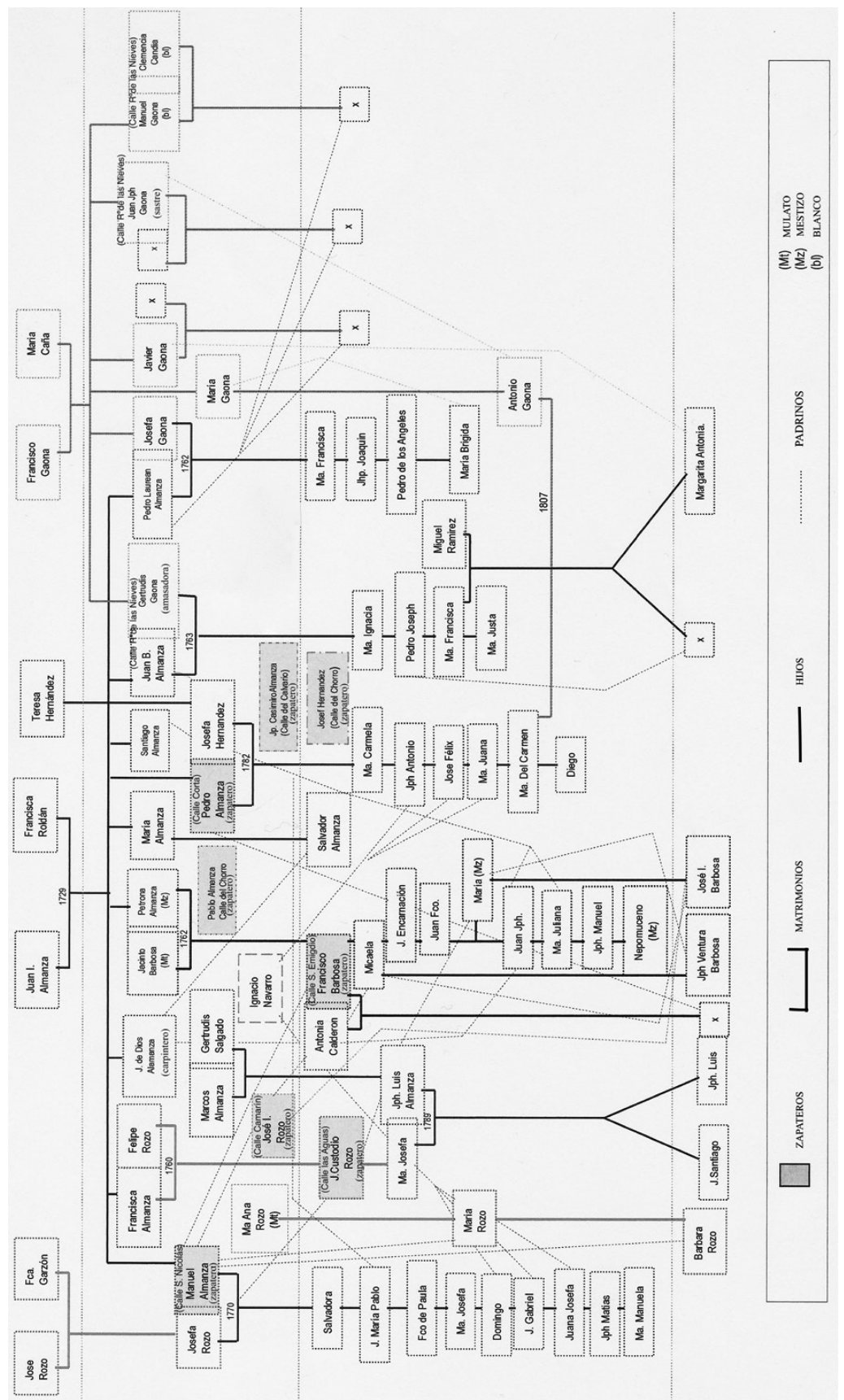

FUENTE: fabricación propia a partir de las listas de milicia y del censo barrial ya citado Datos complementados con los registros parroquiales de matrimonios y bautismos de Nuestra Señora de las Nieves: APN (1760-1810), 08B, 08B-A, 05B, 05Misc., 09B, L.02M, L01M. 
no permite ir más allá de esta constatación general, lo único que se podría afirmar es que, en una parte de esta red de familias, en el tiempo de una generación (entre las dos listas analizadas hay un máximo de 20 años), el oficio de zapatero fue común. Sin que sea posible determinar con esta constatación ni la importancia relativa de los zapateros entre los oficios (no conocemos los oficios de todos los individuos presentes), ni su estabilidad en el tiempo (no tenemos datos anteriores ni posteriores de oficios en esta red).

Otro aspecto que aparece al reconstituir el entretejido de redes familiares es una clara división en dos subgrupos. Del lado de los Almanza emparentados con los Rozo y Barboza (ver diagrama), la prole es en general numerosa, las relaciones parecen estrechas por su redundancia y entrelazamiento con vínculos como el padrinazgo entre sus miembros; del lado de las alianzas con los Gaona (dos hermanos Almanza se casan con dos hermanas Gaona en 1762 y 1763), por el contrario, no hay padrinazgos que unan las dos partes de la familia. Vemos además que ninguno de los zapateros de la familia se relaciona con esta parte. El único vínculo encontrado, más allá de los dos hermanos Almanza que se integran a la familia Gaona, es el matrimonio en 1807 de una hija de Pedro Almanza y Josefa Hernández (María del Carmen), con un hijo natural de María Gaona (Antonio Gaona). La división aparece aún más clara cuando notamos que en los registros parroquiales, o en las listas estudiadas, se da la referencia de pertenecía a las llamadas «castas» (mulatos o mestizos) entre los Rozo, los Barboza y los Almanza.

La pertenencia a las «castas» no está siempre presente en los registros dentro de las mismas unidades familiares, donde en principio la situación es idéntica. Por ejemplo, los hijos de Francisco Barboza (mulato) y de Petrona Almanza (mestiza), cuya descendencia debería ser toda igualmente mestiza, sólo aparece la referencia del «color», en el registro de dos de sus siete hijos (María y Nepomuceno). Esta situación que quizás tiene una explicación tan simple como que en el momento de registrar el bautizo el cura escribió aquello que percibió según sus códigos culturales: pieles más claras o más oscuras, rasgos más o menos aindiados o negroides, nos alerta sobre la manera como entendemos de común la asignación entre las castas. Para este tipo de prácticas parecen poco adecuadas las explicaciones sobre abstractos criterios de sangre, de posición jurídica, de inscripciones mecánicas en casillas predeterminadas; para entrar en estas complejidades conviene pensar la jerarquización racial más bien como proceso social, con sus contradicciones, relatividades y diferentes maneras de expresarse. Pero volvamos a nuestra red, del lado de los Gaona en alianza con los Almanza en ningún momento se hace alusión a una pertenencia a las «castas»; al contrario, sobre Manuel Gaona y su mujer Clemencia Candía se indica que son «blancos». Acorde con las dos diferenciadas ramas de esta red de familias, los pocos oficios que hemos podido definir indican del lado los Rozo-Almanza-Barbosa, además de los zapateros, un carpintero; mientras que del lado de los Gaona-Almanza, aparece un sastre y una amasadora (panadera). Se trata de distinciones en la proximidad que parecen estar indicando una parte más prestigiosa en la misma familia. Otro aspecto que indica jerarquía dentro del mismo grupo de familias es el lugar donde viven.

En la figura 2 indicamos las calles de habitación presentes en las listas y en los documentos consultados. Vemos que los Gaona (Gertrudis, Manuel y Juan Joseph) viven en la 
FiguRA 2. Calles de habitación en Las Nieves occidental: Círculos las familias Almanza-RozoBarboza y cuadrado la Gaona.

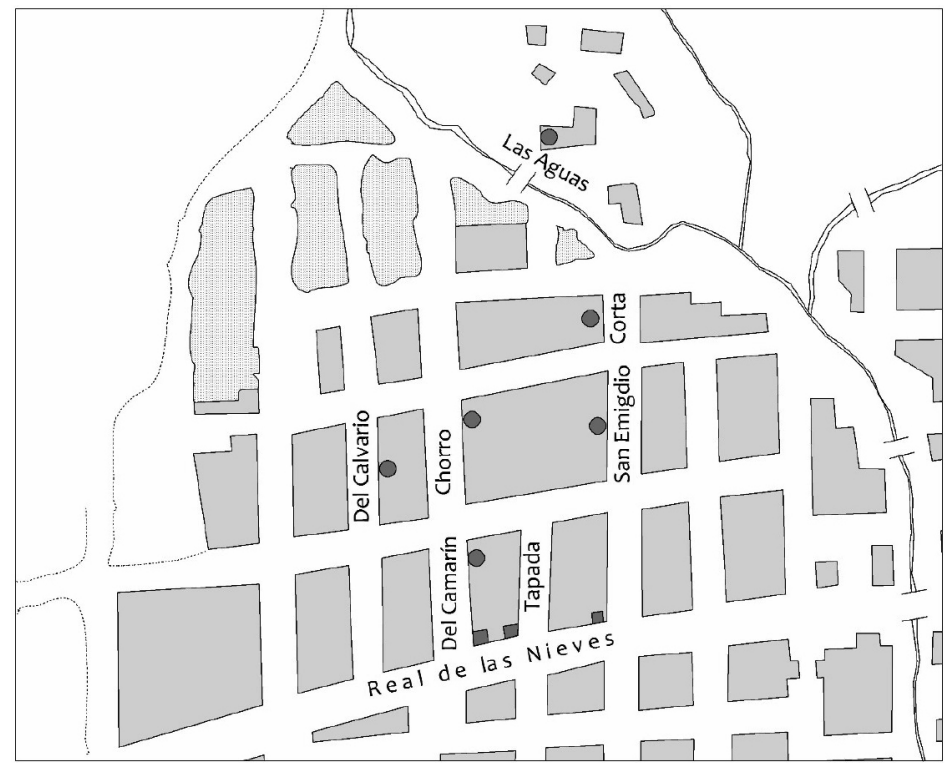

FuENTE: Elaboración del arquitecto Álvaro Erazo a partir de un fragmento del Plano geométrico de la ciudad de Santafé (ca. 1790) del Servicio geográfico del ejército (Madrid). Cf. «Atlas histórico de Bogotá», Historia, vol. 133, Bogotá, 2001, p. 5 y de la información del censo barrial y de las listas de milicias ya citadas.

calle central del barrio (y de la ciudad) «calle Real de las Nieves», mientras que los Rozo, Barboza y Almanza habitan en la parte más periférica: calle del Chorro, San Emigdio Corta, del Calvario o las Aguas de lado de los arrabales. Esta ubicación refuerza lo que decíamos sobre el prestigio de una parte de la red de familias.

Además de la vecindad, los vínculos entre hermanos sobresalen como uno de los puntos de convergencia de estos trabajadores. El compadrazgo se da en general entre hermanos, las madres solteras refuerzan sus relaciones fraternales (con hermanos o hermanas) por la vía del apadrinamiento de sus hijos. Siguiendo esta modalidad parece probable que esta cercanía abarque también solidaridades y alianzas en el trabajo. Otros datos del censo barrial van en el mismo sentido, hay una recurrente alusión a hermanos o hermanas ejerciendo el mismo oficio: Antonia Acosta es costurera y «vive con su hermana también costurera»; Concepción Ferro es tabaquera y «vive con su hermana»; María Guerra, lavandera y «vive con su hermana también lavandera»; Marcelino Gutiérrez, zapatero vive con «dos hermanos zapateros». ${ }^{61}$ Así, las relaciones entre hermanos parecen 
estructurar las alianzas y los vínculos de trabajo, el mundo del trabajo en estas sociabilidades parece estructurarse a partir de relaciones familiares y de habitación, relaciones que se pudieron complementar con la vecindad o con la unión de pertenecer a una misma parroquia, a una cofradía o incluso con frecuentar las mismas tiendas y chicherías.

Si desde un punto de vista, estas «maneras de trabajar» podían parecer socializadas, por lo familiares y comunitarias, desde otro punto de vista percibimos que con este tipo de relaciones de trabajo no se desarrollaban espacios especializados de formación y ejercicio de los oficios. Es decir, en lugar de tener dinámicas de asociación en talleres o tiendas donde la construcción de un «nosotros», en tanto zapateros o costureras fuera factible, se trabajaba dentro de la sociabilidad familiar y de vecindario. Es justamente en este sentido que decimos que los oficios y sus prácticas no eran en la Santafé tardo-colonial elementos eje en la organización del trabajo, ni de los ritmos de vida en la ciudad. Aclaramos que esto no quiere decir que los oficios o el trabajo no fueron importantes, simplemente dice que en ese momento otros referentes de estructuración social tenían más peso: los lazos familiares, de vecindad, de lugar de origen, cofradías, compadrazgo, jerarquía de «castas», la fidelidad a un patrón. Según el caso, el tipo de oficio y el momento, los oficios se pudieron articular con uno o varios de estos aspectos, estructurando -en las efectivas relaciones establecidas - las maneras de trabajar en la ciudad, sus límites y sus posibilidades.

Esta puntual incursión en los vínculos entre zapateros del barrio Las Nieves, nos incita a realizar aproximaciones similares en relación a otros oficios, a otras vecindades y parentescos. Sin ir más lejos, en el mismo caso que acabamos de exponer, surgen aspectos que valdría la pena profundizar, como lo es la manera en la que madres solteras de las cuatro familias (María Ana Rozo, María Rozo, María Almanza, Micaela Barbosa, María Barbosa, María Gaona), mujeres que seguramente debieron trabajar para sustentar a sus hijos, se vincularon en relaciones de comadrazgo entre ellas y de compadrazgo con sus hermanos varones ¿qué tipo de sociabilidades nos puede mostrar el seguir estas pistas? ¿qué dependencias y que autonomías pudieron tener estas mujeres trabajadoras?

\section{Conclusión}

Las maneras diversas y mestizas de trabajar en la ciudad de Santafé de Bogotá a finales de la colonia, dan cuenta de ciertos rasgos característicos. En este artículo destacamos la modalidad del trabajo múltiple, la movilidad de los trabajadores y la escasa asociación en torno a oficios y talleres. Hablamos de relaciones de trabajo marcadas por la inestabilidad y la poca especialización de una población trabajadora, en la que se destaca una significativa y activa mayoría femenina. A lo largo del siglo XVIII el ideal de una buena parte de las relaciones de trabajo en la ciudad pasó de la obligación tributaria a la necesidad de un nuevo control mediante ordenamientos urbanos y gremiales, transformación articulada al crecimiento de la ciudad, a la transformación de su población y a las valoraciones que trajo el reformismo ilustrado a partir de la segunda mitad del siglo. En este 
contexto, las efectivas relaciones de trabajo daban cuenta tanto de la flexibilidad como de las rigideces de su particular configuración, pues si las situaciones eran en efecto variables y relativas, las posibilidades de estos hombres y mujeres no eran tampoco infinitas; muy al contrario, respondían de manera directa a los limitados recursos y posibilidades que les ofrecía el entorno económico, relacional, cultural y político en el que vivían.

Al final del siglo, la documentación que hemos analizado permite afirmar que decir «sastre», «zapatero», «costurera» o «albañil», no remitía necesariamente a realidades sociales o económicas homogéneas, ni a grupos socio raciales bien definidos y diferenciados, como se suele suponer. Esta afirmación lejos de quitarle importancia al «oficio» o de eliminar el peso de las «castas», permite adoptar una perspectiva atenta a la formación de las diversas jerarquías que cruzaron el mundo del trabajo capitalino. En este artículo empezamos con un acercamiento a los oficios a partir de listados y terminamos con la reconstitución de una red de familias mestizas donde el oficio de zapatero fue muy frecuente hacía finales del siglo XVIII. Las relaciones que pudimos aproximar pusieron de relieve, en un barrio popular como el de las Nieves, un particular tejido entre tipos de oficios y prestigio, entre sociabilidades y jerarquización racializada, entre jerarquías familiares y de trabajo; relevaron la importancia de la vecindad y del parentesco en la organización del trabajo e indicaron que las relaciones entre hermanos primaban en las asociaciones tanto de trabajo como de compadrazgo. Preguntarse por las «maneras de trabajar» de los santafereños, representa así dos búsquedas: de un lado ir más allá de las categorías para pensar las relaciones sociales de trabajo y, del otro, explorar aspectos de la vida económica de los santafereños que resultan poco visibles desde historiografías clásicas construidas en función de instituciones, de estructuras, de reglamentaciones o de ideologías. En esta dirección ciertas pistas fueron abordadas o identificadas, pero es evidente que un largo camino queda aún por explorar.

Asumir los aspectos económicos de la vida (trabajo, tierra, impuestos, comercio, entre otros) para entender una sociedad era una idea que no debía defenderse una generación atrás. Muchos de estos temas, que parecían aún centrales a finales del siglo Xx, hoy parecen haber desaparecido de muchas agendas académicas en ciencias sociales. «Los proceso no se dan en el aire», solía decirle Juan Carlos Garavaglia a sus alumnos, esta afirmación que parece simple, incluso podría decirse banal, conlleva hoy el desafío de retomarla en las actuales prácticas de la investigación histórica ¿De qué manera el aspecto económico de la vida social del pasado se piensa hoy en diálogo con las problemáticas de renovadas historiografías políticas, jurídicas, intelectuales o culturales? ¿Es un asunto de temáticas, de interdisciplinariedad o de maneras de concebir el conocimiento? ¿Qué es lo determinante y qué lo derivado? ¿Hay un aspecto determinante? ... Más que una respuesta precisa, lo que siempre fomentó Juan Carlos en sus alumnos fue la doble responsabilidad de no abandonar y —al mismo tiempo- la de no «esencializar»o «cosificar» este aspecto de las dinámicas sociales. La comprensión que hemos intentado en estas páginas se inscribe en este horizonte de investigación. Seguir pensando lo que le interesaba pensar a Juan Carlos es, como lo plantea este encuentro, la mejor manera de recordarlo. 


\section{Fuentes}

Fuentes de archivo:

Archivo General de la Nación (AGN). Bogotá, Colombia.

Sección Colonia,

Fondos:

Policía, tomos 3 y 11.

Testamentaria, tomos 13 y 8 .

Civiles, tomo 7.

Criminales, tomos 73 y 100.

Miscelánea, tomos 2, 3 y 37.

Moneda, tomo 1.

Mejoras Materiales, tomo 9.

Milicias y Marina, tomos 12, 18, 141

Notaría 3. ' de Bogotá, tomo 366 (1825).

Archivo de la Parroquia de Nuestra Señora de las Nieves (APN). Bogotá, Colombia. Años 1760-1810:

Libros 09B, 08B, 08B-A, 05B, 05 Misc., L02M, L01M.

\section{Fuentes Impresas}

«Atlas histórico de Bogotá», Credencial Historia, n. 133, Bogotá, 2001.

Caballero, J. M., Particularidades de Santa Fé, un diario de José María Caballero, Bogotá, Biblioteca Popular de Cultura Colombiana, 1946.

Correo Curioso. Erudito, Económico y Mercantil (1801) —ed. facsimilar—, Bogotá, Biblioteca Nacional, 1993.

Codovez Moure, J. M., Reminiscencias de Santafé y Bogotá, Bogotá, Librería Americana, 1899.

Holton, Isaac, La Nueva Granada, veinte meses en los Andes, Bogotá, Banco de la República, 1981.

Solórzano y Pereyra, Juan, Política Indiana, Madrid, Biblioteca de autores españoles t. 253, 1972.

Steuart, John, Narración de una expedición a la capital de la Nueva Granada y residencia allí de once meses. Bogotá en 1836-37, Bogotá, Academia de Historia /Tercer Mundo, 1989.

Tovar, Hermes, Jorge Tovar Mora y Camilo Tovar Mora (comp.), Convocatoria al poder del número: censos y estadísticas de la Nueva Granada, 1750-1830, Bogotá, Archivo General de la Nación, 1994.

\section{Bibliografía}

Alberro, Solange, «Familia y trabajo en la Nueva España, las ambigüedades del tema», França Paiva, Eduardo y Carla Anastasia Jubho (eds.), O Trabalho Mestiço. Maneiras de pensar e formas de viver, séculos XVI a XIX, São Paulo, Universidade federal de Minas Gerais, 2002, pp. 513-524.

Alzate, Adriana María, «La chicha: entre bálsamo y veneno. Contribución al estudio del vino ama- 
rillo en la región central del Nuevo Reino de Granada, siglo XVIII». Historia y Sociedad, vol. 12, Bogotá, 2006, pp. 161-189.

Bonnett, Diana, «Oficios, rangos y parentesco. Los trabajadores de la Casa de la Moneda de Santafé 1620-1816». Historia y Memoria, vol. 6, Bogotá, 2013, pp. 103-141.

Cerutti, Simona, «Du corps au métier: la corporation des tailleurs à Turin entre XVII et XVIII siècle». Annales ESC, Paris, vol. 2, 1988, pp. 323-352.

Colmenares, Germán, «La economía y la sociedad coloniales, 1550-1800», en Nueva Historia de Colombia, t. I., Bogotá, Planeta, 1989.

Dueñas, Guiomar, Los Hijos del Pecado, ilegitimidad y vida familiar en la Santa Fe de Bogotá colonial, Bogotá, Universidad Nacional, 1997.

Fajardo de Rueda, Marta, Oribes y plateros en la Nueva Granada, León, Universidad de León - Secretariado de Publicaciones, 2008.

França Paiva, Eduardo y Carla Anastasia Jubho (eds.), O Trabalbo Mestiço. Maneiras de pensar e formas de viver, séculos XVI a XIX, São Paulo, Annablume / Universidade federal de Minas Gerais, 2002.

Gruzinski, Serge y Carmen Bernard, Histoire du Nouveau Monde, II Les métissages, Paris, Fayard, 1993.

Gutiérrez, Virginia y Roberto Pineda, Miscegenación y Cultura en la Colombia colonial. 1750-1810, t. 1. Bogotá, Uniandes / Colciencias, 1999.

Jaramillo, Jaime, «La economía del virreinato (1740-1810)». Ocampo, José Antonio (ed.), Historia Económica de Colombia, Bogotá, Siglo Veintiuno Editores - Fedesarrollo, 1987.

Kalmanovitz, Salomón y Edwin López, «La Economía de Santafé de Bogotá en 1810», Revista de Historia Económica, vol. 30, n. 2, Bogotá, 2012, pp. 191-223.

Lévi, Giovanni, «Carrières d'artisans et marché du travail», Annales ESC, n.6, Paris, 1990, pp. 1351-1368.

López Bejarano, Pilar, Gente ociosa y malentretenida: Trabajo y pereza en Santafé de Bogotá, siglo XVIII», Bogotá, Universidad de los Andes, Ediciones Uniandes, 2019.

-, «Control y desorden en Santa Fe de Bogotá (Nueva Granada). En torno a las Reformas urbanas de finales del siglo XVIII», BROCAR - Cuadernos de Investigación Histórica, vol. 30, La Rioja, 2006, pp. 111-137.

-, «Dinámicas mestizas, Tejiendo en torno a la jerarquía, al trabajo y al honor. Nueva Granada, siglo XVIII», NuevoMundo, Mundosnuevos, Paris, 2008, en línea: <http://nuevomundo.revues. org/index19263.html>.

Martínez, Carlos, Santafé, capital del Nuevo Reino de Granada, Bogotá, Banco Popular, 1987.

McFarlane, Anthony, Colombia antes de la independencia, economía, sociedad y política bajo el dominio Borbón, Bogotá, Banco de la República / El Áncora Editores, 1996.

Moses, Finley, L'économie antique, Paris, Minuit, 1973.

Palacios, Marco y Frank Safford, Colombia: país fragmentado, sociedad dividida, Bogotá, Editorial Norma, 2002.

Ramírez, María Himelda, Las Mujeres y la Sociedad Colonial de Santa Fe de Bogotá, 1750-1810, Bogotá, Instituto Colombiano de Antropología e Historia, 2000.

Rodríguez, Diana, El trabajo artesanal en Santafé durante la primera mitad del siglo XVII: sastres, zapateros y sombrereros. Bogotá: Tesis de maestría en historia, Universidad de los Andes, 2015.

Russell-Wood, A. J. R., «La mujer y la familia en la economía y en la sociedad del Brasil durante la 
época colonial», en Lavrin, Asunción (comp.), Las mujeres latinoamericanas, perspectiva histórica, México, Fondo de Cultura Económica, 1985, pp. 74-120.

Sánchez-Albornoz, Nicolás, La población de América Latina: desde los tiempos precolombinos al año 2000, Madrid, Alianza Editorial, 1973.

Serulnikov, Sergio, «El fin del orden colonial en perspectiva histórica. Las prácticas políticas en la ciudad de La Plata, 1781-1785 y 1809», Revista Andina, n. 52, Cusco, 2015, pp. 9-47.

Silva, Renán, «La crítica ilustrada de la realidad en las sociedades andinas». Garrrido, Margarita (ed.), Historia de América Andina, vol. 3: El sistema colonial tardío, Quito, Universidad Andina Simón Bolívar, 2001, pp. 361-394.

Solano, Sergio, «Artesanos, Jornaleros y formas concertadas de trabajo: el Apostadero de la Marina de Cartagena de Indias (Nuevo Reino de Granada) en el tránsito entre los siglos XVIII y XIX», THEOMAI, vol. 31, Cartagena, 2015, pp. 79-105.

Testart, Alain, L'esclavage, la dette et le pouvoir, Paris, Errance, 2001.

Vargas, Julián, «Santa Fe a la luz de sus padrones (1778-1806)», en La sociedad de Santa Fe Colonial, Bogotá, CINEP, 1990, pp. 11-45.

Vargas, Julián y Marta Zambrano «La población indígena de Santafé»., en La sociedad de Santafé colonial, Bogotá, CINEP, 1990, pp. 47-84.

Zambrano, Marta, «Trabajo preciosos y trabajadores despreciables: prácticas conflictivas y consenso epistémico en el discurso colonial», ACHSC, vol. 25, Bogotá, 1998, pp. 6 a 34. 